\section{Diálogos paradigmáticos sobre informação para a área da saúde. Virgínia Bentes Pinto e Henry de Holanda Campos (Orgs). Fortaleza: Edições UFC, 2013, 444p.}

\section{Elenice M. Cunha}

Escola Politécnica de Saúde Joaquim Venâncio, Fundação Oswaldo Cruz, Rio de Janeiro, Brasil

$<$ elenc@fiocruz.br>

A relevância da área de Informação e Informática em Saúde (IIS) para o alcance dos princípios do SUS e melhoria de sua efetividade é indiscutível. Entretanto, o desenvolvimento da IIS, por sua transdisciplinariedade, depende da contribuição de referenciais de distintas áreas do saber. A obra Diálogos paradigmáticos sobre informação para a área da saúde, organizada por Virgínia Bentes Pinto e Henry de Holanda Campos, veio ao encontro dessa necessidade.

De início, prefácio e apresentação promovem de forma consistente a familiarização com a amplitude e interfaces do objeto 'informação em saúde' e com o conjunto dos capítulos e temáticas abordadas. O livro, com mais de quatrocentas páginas e 15 capítulos, abrange tanto questões teórico-metodológicas para abordagem do objeto quanto discussões e definições mais diretamente relacionadas à prática dos serviços, com ênfase em questões relativas aos requisitos das Ciências da Computação.

Pela abrangência da obra, a nossa opção foi por destacar os capítulos iniciais, que tratam de temáticas que supostamente profissionais e pesquisadores da saúde estejam menos familiarizados. O primeiro capítulo apresenta uma proposta de modelo de análise para o objeto 'informação em saúde'. A análise de domínio, abordagem teórica e metodológica de uso corrente nas Ciências da Informação, teria duas etapas bem demarcadas. A primeira etapa, em que se buscaria entender e descrever o escopo e abrangência do objeto com base na análise de suas premissas ontológicas, epistemológicas e sociais, encontra-se de forma mais detalhada e em uma aproximação com o objeto. Já a segunda etapa da análise, que supostamente permitiria intervir sobre as informações do domínio em questão, não chega a ser discutida. Há apenas a menção de que esta consiste em um "conjunto de metodologias" (p. 35) de uso frequente na Ciência da Informação.
Para os que não estão familiarizados com estudos no campo da Ciência da Informação e com a complexidade do objeto 'informação em saúde', a compreensão do capítulo exige dedicação e releituras. Contudo, o esforço é recompensado, posto que conceitos e proposta de análise apresentados lançam luzes sobre a complexidade do objeto e sobre implicações de tê-lo como objeto de pesquisa.

De perspectiva mais geral e abrangente, o segundo capítulo contextualiza a chamada 'sociedade da informação' na atualidade, com destaque para características como a interatividade e o compartilhamento, que modificam e ampliam as possibilidades de 'saber, produzir e atuar' dos indivíduos. Tais possibilidades, que estariam condicionadas pelo desenvolvimento de tecnologias digitais, juntamente com a sobrecarga de dados, promoveriam impactos na prática da medicina, permitindo, ou exigindo, modificações no padrão de atuação de profissionais e pacientes. A abordagem, em linguagem clara, amplia a compreensão e contribui para superar uma perspectiva tecnicista do objeto 'informação em saúde'.

O terceiro capítulo, "Informação para o monitoramento de risco em saúde", de abordagem mais prática, apresenta um panorama do que seria o uso das informações e a aplicação das tecnologias de informação e comunicação (TICs) no Sistema Único de Saúde, sem muitas novidades para aqueles profissionais do setor saúde que já atuam na área, mas provavelmente contribuirá para profissionais da Ciência da Informação e das Ciências da Computação que tenham interesse no tema 'informação em saúde'.

O quarto capítulo contempla discussão atual, que, no âmbito do setor saúde, precisa ser ampliada e aprofundada: o acesso livre à informação científica. No texto, a autora explicita fatos e situações que têm contribuído, no Brasil, para o movimento em favor do acesso livre à informação, como a abertura política, a crise econômica e o desenvolvimento das TICs; e ainda eventos e discussões, em âmbito nacional e internacional, relevantes para o desenvolvimento da questão. Reforça os repositórios institucionais como projeto que possibilita a implementação da ideia como política de apoio ao desenvolvimento científico e à democratização do acesso ao conhecimento, mostrando potencial para impactar positivamente na atenção à saúde. 
O capítulo quinto trata da possibilidade e necessidade da representação indexal para o tratamento informacional do prontuário do paciente. Requer esforço, não para a compreensão do texto, mas para motivar-se à leitura, pois, embora básica na Ciência da Informação, a temática é pouco abordada no setor saúde, e não estamos familiarizados com ela. Contudo, deve-se ter em conta, na leitura e compreensão da obra, que é preciso empenho para desenvolver o objeto 'informação em saúde', dadas as interfaces da temática. O texto é elucidativo na medida em que esclarece aos iniciantes a funcionalidade e relevância da representação indexal, que em síntese agiliza a recuperação da informação.

Os capítulos seguintes discutem terminologias e padronização. Um desses capítulos, inicialmente escrito no idioma espanhol, apresenta resultados de trabalho empírico sobre identificação de termos representativos da linguagem médica especializada, por profissionais supostamente envolvidos com a questão, e relata a falta de consenso e outras dificuldades. A certa atura, no entanto, esse capítulo traz trechos em catalão, o que dificulta a compreensão do texto em sua totalidade, posto que é um idioma pouco falado no Brasil.

Arquitetura da informação em meio digital e interoperabilidade dos sistemas também são temas abordados na obra, em uma linguagem clara que possibilita a compreensão mesmo por aqueles ainda não familiarizados.

No último capítulo, os autores explicitam alguns dos dilemas e implicações da informatização dos documentos gerados nas instituições de saúde. Destacam que o prontuário do paciente não é o único documento produzido nessas instituições, pois a maioria dos processos de trabalho administrativos também geraria documentos. Nesse aspecto ressalta a importância do referencial analítico e organizativo da disciplina Gestão de Documentos. Apresenta, de forma sucinta, a legislação e instituições que deveriam nortear o processo de informatização e os possíveis interesses envolvidos.

A superação das limitações da IIS depende menos de iniciativas pontuais internas ao campo específico da saúde e mais de outros referenciais. Visto por uma profissional de saúde que se ocupa da Educação Profissional na área de Informações e Registros em Saúde, pelos temas abordados, a obra assume grande importância.
Por sua abrangência temática e consistência teórica, o livro tem potencial para servir de referência para pesquisas e como subsídio para o ensino. 